\title{
PAINTING PICTURES: TOWARDS CONNECTING THROUGH IMAGERY IN DIALOGUES WITH YOUNG PEOPLE WITH INTELLECTUAL DISABILITY
}

\author{
Hanna Peels and Sofie Sergeant
}

\begin{abstract}
The authors discuss pivotal themes in the use of imagery (visual and verbal) as a method to engage in dialogue with young people with intellectual disability (ID). In their discussion they reflect on co-occurring changes in Dutch society, the nature of caregiving, and the increasing appeals for empowerment for and by people with ID. A critical dialogue is used to analyse experiences with imagery from their previous research, and the possibilities imagery harbours to improve dialogues on quality of life with young people with ID. Through analysis of the critical dialogue, five themes were identified: leitmotiv, ambiguity, choice, revelation, and distance. To conclude, the authors discuss why family members and professional support workers should consider using imagery as a productive methodology.
\end{abstract}

Keywords: imagery, dialogue, quality of life, metaphors, blogs, drawing lab

Acknowledgements: The authors wish to thank Geert van Hove, Petri Embregts, and Alice Schippers for their critical remarks and support and especially to Mitzi Waltz for her detailed comments. We wish to thank Beau for granting permission to quote excerpts from her blogs. We would also like to acknowledge the very helpful comments on previous versions of this paper which were provided by anonymous referees.

Hanna Peels MSc (the corresponding author) is a psychologist at Middin (a service provider for people with intellectual and physical disabilities) and a PhD Researcher at the Free University Amsterdam, Prinses Beatrixlaan 16, 2285 VZ Rijswijk, The Netherlands. Email: h.peels@middin.nl

Sofie Sergeant MSc is a PhD researcher at the Free University Amsterdam and the Education Coordinator at Disability Studies in the Netherlands, Stadsring 2 / Meet \& Discover, 3811 HR Amersfoort, The Netherlands. Email: sofie.sergeant@disabilitystudies.nl

Note: Both researchers contributed equally, and are therefore considered co-first authors. 
International Journal of Child, Youth and Family Studies (2018) 9(4): 125-145

A new Soap Bubble Syndrome has been born, a beautiful dream bursts with an unmistakable bang and consequently takes itself out. At that point I often cannot but lament that when I do not imagine, I will not be anything. ${ }^{1}$ (Beau, 2010b, sentences 15-16)

The metaphoric language of Beau, written in an online blog about living with disabilities, provides vivid examples of imagery. Imagery in any form elicits an instant connection between people that evokes the need for interpretation. The power of imagery, or the ability to narrate with images in different modalities, has been well explored through visual images (Stanczak, 2007; Wang, Yi, Tao, \& Caravano, 1998), music (Howe, Jensen-Moulton, Lerner, \& Straus, 2015), verbal narratives and metaphors (Stefán, 2010; Dunn \& Burcaw, 2013), dance (Hermans, 2016), and other means. Less research has been conducted on the role of imagery in discussions about existential topics, such as life, meaning, purpose, and the future, between young people with intellectual disabilities and their friends, their families, and professionals. However, discussion of these topics is essential to shape support for young people with ID and to improve their quality of life (QOL), especially in domains such as emotional well-being, interpersonal relations, and selfdetermination (IASSIDD SIRG-QOL, 2000). All people, with or without ID, think about their lives and what they want in life. Atkinson (2005) stated that, "Life stories, and the opportunity to tell them, are particularly important for people with learning disabilities because often they have been silent, or silenced, while other people - families, practitioners, historians - have spoken on their behalf." (p. 7). The opportunity to tell life stories, and discuss them with other people, is an opportunity that does not always come naturally for young people with ID. Although family members and professionals may presume that they have a fairly good view of what is going on in a young person's life, the use of imagery in discussing life stories can be a surprisingly revealing and confronting method for challenging these presumptions. Using imagery as a method to discover new information (as with the use of blogs, diaries, photo-elicitation, photovoice, etc.) forces the other in the dialogue to relate to the distinctly different position that the young person with ID may have in life, and his or her personal interpretation of life events.

The objectives of this study were to:

1. Sketch the (Dutch) context within which the need for an existential dialogue with young people with ID emerges;

2. Explore the power and possibilities of using imagery in research and dialogue by means of a critical dialogue between the researchers; and

\footnotetext{
${ }^{1}$ Beau granted permission to use excerpts (translated from Dutch to English) from her blog in this article. The translation was done by one of the authors in consultation with Beau; the translated excerpts were presented to Beau before using in this article.
} 
International Journal of Child, Youth and Family Studies (2018) 9(4): 125-145

3. Give practical directions for family and support workers to create an environment in which imagery can be used as a method to engage in dialogue.

\section{Background}

\section{Changing Landscape of Care and Support Strategies}

Working with young people with ID in the Netherlands has changed drastically from the starting point of charitas [charity]. For centuries, medical care has been at the very core of support for Dutch people with disabilities. Since in this model the person with disabilities was seen as a "victim" of the disability, the focus of support was to find a cure. Since the 1960s, a new socialecological perspective on disability has gradually emerged in the Netherlands, following the rise of advocacy movements in America, the Netherlands, and elsewhere, and developments in disability studies. This perspective no longer classifies disability as a trait of the person involved, but as a concept that is constructed and influenced by the society in which the person lives (Brants, van Trigt, \& Schippers, 2016; Hoppe, 2012). The social-ecological perspective prompts professionals to develop new support strategies for young people with ID based on concepts of reciprocity and equivalence. People with ID are seen as experts by experience: they have useful knowledge to share (De Waele, van Loon, Van Hove, \& Schalock, 2005). Ideally, professionals and caregivers are no longer in the decision-making position when it comes to support; the Dutch (and global) advocacy movement of people with ID has made clear that they have a basic human right to be in charge when it comes to their lives.

\section{High Demands in Society}

In the Netherlands, being able to participate without support is more challenging now than in past decades, due to the fast pace of societal development and high societal demands on citizens. This development has been reported by the Dutch National Institute for Health Services Research (NIVEL) in a 2015 report (Speet \& Rijken, 2005), and similar concerns were raised by Dowse (2009). In public debates there is much discussion of taking control of one's life. Even in these ideologically driven debates, there is an overtone that tacit expectations should be met by people with ID and their caregivers: despite their apparent disabilities, they should be obliged to meet the participatory requirements of a rapidly changing society — and their family members should feel equally obliged to support them in this participation. The fastidiousness of society therefore places a huge pressure on young people with ID and their families to transcend their disabilities, to (be able to) participate. However, as the Dutch national self-advocacy group for people with intellectual disabilities (the LFB) notes, while there may be ample opportunities for inclusion, the tacit views of other people in society, especially professionals, hinder inclusion (Speet \& Rijken, 2005).

\section{Disability and Communication}

For young people with ID, difficulty with producing and understanding more complex language can lead to friction with family, friends, and professionals (Lewis, Gaffney, \& Wilson, 
2016). Therefore, much emphasis in the Dutch context of support is placed on training individuals to acquire a functional level of verbal language. In the light of recent insights into Universal Design (Null, 2013) and Universal Design for Learning (Nelson, 2014), this emphasis on functional verbal communication falls short when it comes to dialogues about the meaning of life, achieving a sense of belonging, and discussing QOL issues. Even though people in the field recognise the potential of approaching these themes using tools that are better suited for the communication abilities and styles of people with ID, the application of new ways of communication in daily practice still seems to be uncommon (Williams, 2011). In the field of working with people with disabilities, most instruments or programmes that address a thorough conversation with the individual with ID seem to be focused on producing an outcome that will give the family or professional practical tools to shape support for the young person.

These programmes and instruments are certainly useful, but they fall short of building a true bridge between youngsters with ID and their dialogue partners (Sergeant \& Verreyt, 2016). A clear example is the use of pictograms, which are used to support both receptive and expressive communication of people with ID. However, the use of pictograms often focuses on the context of instrumental communication - communicative interactions aimed at gaining certain objectives, or facilitating certain activities or interactions. Therefore, the way pictograms are currently used constrains the potential communicative power of the images to a certain extent. Even if images are used to communicate about emotions, they are mostly used in an instrumental way; for example, to express anxiety or sadness. In the Netherlands, fewer examples are seen where images are used to explore the deepest feelings, meanings, and sense of being of the other: the so-called narrative of life. The assumption that meaningful communication with young people with ID can (or even should) be simplified to unidirectional choices reflects a tacit underlying idea about the abilities of young people with ID, including their ability to engage in complex, diverse, and reflective dialogues.

\section{Method}

The authors of this article have years of experience working in services for people with ID. They have seen on a daily basis the importance of using various forms of communication to connect to people with ID - or people without ID, for that matter. Starting from this position of engagement, both authors are involved in participatory research with people with ID. Sofie Sergeant has been conducting participatory action research. One of the methods she developed is called Tekenlab [Drawing Lab], an inviting environment in which participants (with or without ID) are asked to make a drawing and share their reflections and stories about one of the domains of QOL linked to their personal life (Sergeant \& Verreyt, 2016). Hanna Peels has been exploring the role of people with disabilities in the care system as experienced by people with ID. Her method has consisted of analysing in various ways a blog about the care and health system in the Netherlands in cooperation with "Beau", its author. Beau blogs about her own experiences and 
thoughts on living in a facility for people with physical or intellectual disabilities. In her blog entries, she often uses metaphors and poems to describe emotionally charged experiences.

The authors noticed that even though the forms of imagery used in their respective research differ, their experiences with using imagery in research were similar: the advantages of using imagery seemingly transcend the form. The decision was therefore made to explore these advantages by critically questioning each other through the method of a critical dialogue. Karlsson (2001) described the critical dialogue as a process "where the individual examines and verifies his/her own and others' perspectives and assumptions" (p. 225); he also stated that "the discourse of dialogue is an exchange of ideas and meanings, and the purpose is of learning more than judging” (p. 212). The dialogue in this research was critical in nature, given that the authors not only discussed their research cases but endeavoured to come to a closer understanding of each other's research. By engaging in dialogue, the authors compared their respective research (Drawing Lab and blog analysis) as if each of their research projects was a separate "case." In comparing these cases, the authors discussed their own experiences, values, and learning moments in their research. Within the framework of critical dialogue, a general inductive approach (Thomas, 2006) was used to develop a framework for the underlying structure and experiences evident in both cases, and in the dialogue about the cases. The researchers questioned themselves critically on their choice of method, the similarities and differences between critical incidents, the impact their research has had on themselves as researchers, and the way the use of imagery helped and inspired the researchers in their research. Important and recurring key concepts in the dialogue were clustered. This led to five main themes that will be discussed in Findings.

Comparing cases offered each researcher the chance to reflect on her own research as well as evaluating the other's. Following Smaling (2008), the authors kept reminding themselves of the reflexive and analytic nature of their dialogue, and therefore secured empathic cooperation while discussing different insights or arguments. This emphasis on the reflexive nature of the dialogue was an essential step towards using the dialogue in a transformative way. Following Freire (2005) the authors entered the critical dialogue fully aware that their thoughts and ideas would be changed in comparing the cases. Rooted in participative action research, the researchers aim was in fact to change the care and support offered to young people with ID, as well as to improve the ways that researchers can make young people with ID feel welcome to participate in research.

The authors shaped the critical dialogue by using materials gathered into journals they kept during their own research: critical incidents, key quotes, and field notes. To paint a picture of the research that led to the reflexive process described in this article, the authors use quotes and vignettes from their ongoing research. Their joint reflexive process, however, provides the framework for this article.

\section{Target Group}

The critical dialogue revolved around communication with young people with ID. Like Goodley and Runswick-Cole (2014), the authors acknowledge that many people labelled as having 
International Journal of Child, Youth and Family Studies (2018) 9(4): 125-145

ID prefer no labels whatsoever. The term intellectual disability (ID) is used here because it is a common term applied across the globe. In this article, the term "young people" refers to persons between the ages of 15 and 24, following the definition of "youth" given by the United Nations Department of Economic and Social Affairs (n.d.). Young people were chosen as the target group in the critical dialogue because this is an age range during which people experience the transition from childhood to adulthood. This transition is accompanied by existential questions and doubts about, for example, identity, place in society, work life, and relationships.

\section{Ethics}

Informed consent was obtained from all participants in both the Drawing Lab research and the blog-analysis research, following the Disability Studies Netherlands Code of Practice for researchers 2016-2017 (DSiN, 2016). Beau granted permission to use excerpts (translated from Dutch to English) from her blog in this article.

\section{Findings}

We metaphorize, therefore we know. Metaphors are primary in relation to our existence as we know it. (Dolmage, 2005, p. 110).

Both family members and caregivers often search for a useful method to guide discussions about existential questions with young people with ID. The authors' own experiences as both professionals and researchers led them to conclude that imagery offers an attractive, rich, and engaging way of connecting. In their critical dialogue, their communication experiences were discussed, leading to the identification of five themes that apply to both verbal and visual imagery: leitmotiv, ambiguity, choice, revelations, and distance. These five themes reveal the possibilities and strengths of using imagery as a means of communicating with young people with ID.

In presenting these findings, the power of using visual images in engaging in dialogue is disentangled from, and juxtaposed with, that of using metaphors. The argumentative nature of the critical dialogue (Smaling, 2008) is reflected in the structure of the results: each discussion of one of the five themes will start with exploration of the theme in visual images, metaphors, or verbally painted pictures, and conclude with some experiences and thoughts. Vignettes and quotes from previous research are added to illuminate the findings.

\section{Leitmotiv}

The term "leitmotiv" has its origins in music and refers to "the recurring musical themes ... attached to characters, objects, situations, and ideas ... underlying the Wagnerian Gesamtkunstwerk" (Scher, 2004, p. 185). In discussing imagery the authors found that a coherent cluster of important values and convictions resurfaces each time a meaningful dialogue takes place. The entirety of thoughts, needs, and dreams that a person wants to discuss is similar to a leitmotiv in music. The leitmotiv assures both partners in the dialogue that there is no need to push their agenda forward; the agenda will not disappear, but is there to revisit when needed. 


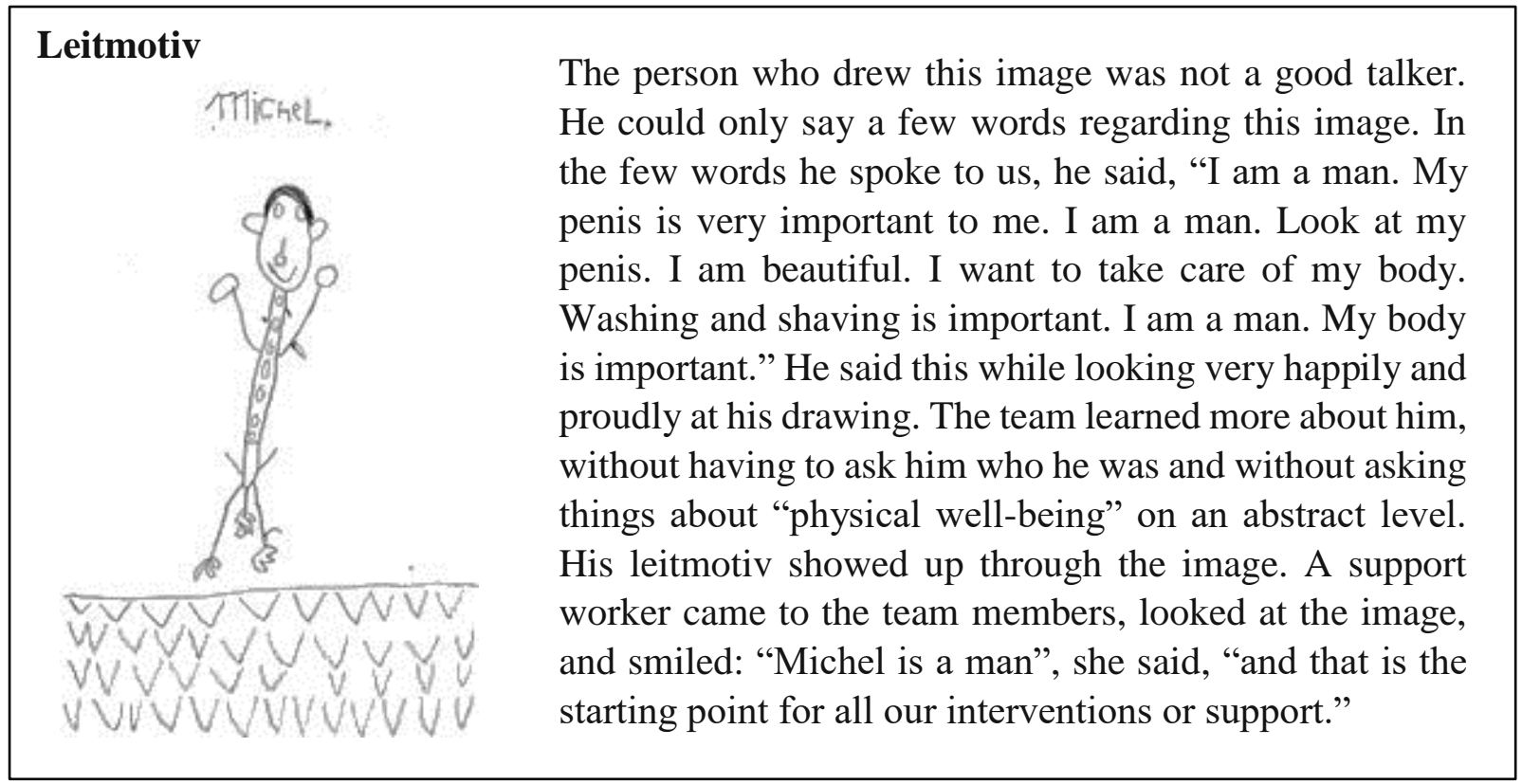

Figure 1. Vignette: Leitmotiv.

The maker of an image has his or her own agenda, a theme or a message to communicate. When confronted with an image, one may choose to follow that agenda, or find a way to avoid it. The image is central to a personal story, and the interpreter is the director of that story. The reader animates and re-animates the storyline and decides how to interpret it. "Metaphors might be seen as bridges on the verbal map. Indeed, the Greek root of the word, metapherein, means 'to carry across'." (Dolmage, 2005, p. 109). Stories are by definition useful in bridging the experiences of different people. Metaphors and stories are often rooted in joint experiences. Using shared language has the power to bring together family, support workers, and young people with ID.

Surpassing the practical use and intention of metaphors in support work is the observation that the use of metaphors is close to the heart and nearly unconscious:

But metaphors are never disinterested. The author submits that there is more going on than just words when metaphors are used. In other words, the argument is that despite our nearly unconscious reception of them, metaphors carry and construct particular social and cultural meanings. (Dolmage, 2005, p. 111)

Consciously or unconsciously, partners in a dialogue look for the agenda of the other while interpreting the product of imagery. Using imagery offers the opportunity to talk about the desired outcome without directly addressing or questioning the truthfulness of the interpretation or agenda of the other. Moreover, since the intended agenda is secured in an object (visual image or metaphor), the important themes for the young person with ID will reappear when needed.

The leitmotiv is an important concept for the simple reason that young people with ID, and their families, live with challenging circumstances. This starts from the moment of diagnosis and 
the beginning of treatment to the experience of an impressive number of professionals entering and leaving their lives. Being able to grasp important themes and to have the certainty that they reappear when needed is a vital part of expressing oneself as a person growing up. Moreover, the leitmotiv ensures an ongoing dialogue between the young person with ID and family members or support workers.

\section{Ambiguity}

Looking at her drawing, the woman in the Drawing Lab talked to the team about the importance of the sun, and warmth in her life. She loved the sun on her skin; she enjoyed walking and wandering through nature. The researcher interpreted the drawing as a person and a house. However, the woman said, "On the right I drew a baby in a pram." The person in the drawing turned out to be a flower. The woman explained about her dream of having her own baby, and the possibility of not being able to reach this dream.

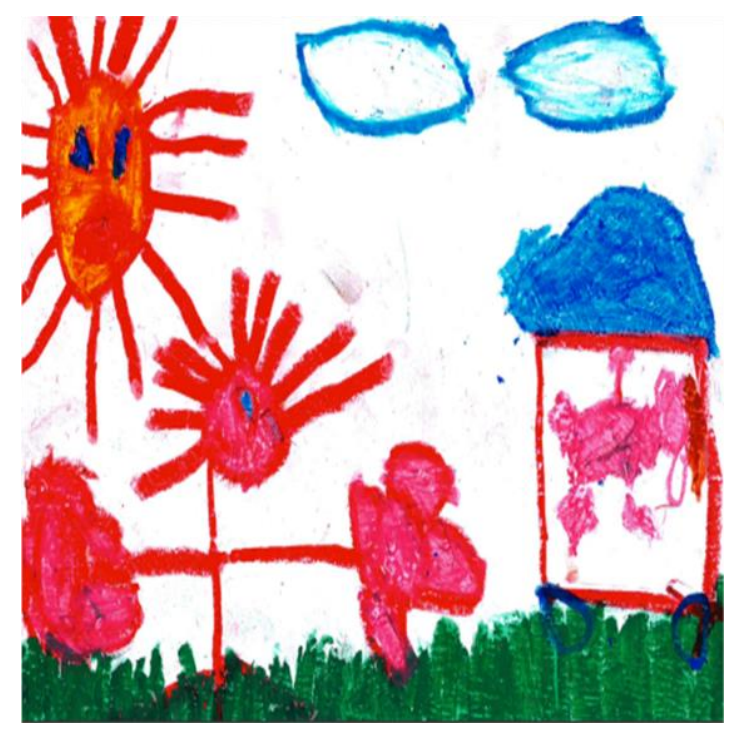

After looking at the picture again, she started talking about the children in her family, of being an aunt and enjoying this role. In the dialogue she gave several meanings and interpretations of this image of the baby in the pram. Her story, and the initial interpretation of the researcher, illustrates the possibility of ambiguously interpreting and reinterpreting the meaning of a drawing and discovering stories hidden in it.

Figure 2. Vignette: Ambiguity.

\section{Ambiguity}

An image may be seen as an inventory of multiple meanings. "Rather than demanding only an objective reading, images also elicit various subjectivities from our participants that — instead of being bracketed away — can be probed and analysed." (Stanczak, 2007, p. 7). The meaning of 
an image is neither steady nor stable. Depending on who a person is, and how one looks at the image, one discovers other things and stories: "Images trigger different insights, depending on the different questions that we ask of them." (Stanczak, 2007, p. 9). Meaning is given from one's own life events, experiences, and prior knowledge. By exploring a drawing, and by drawing further together, more can be discovered with regard to people's own assumptions or autonomous expression (Sergeant \& Verreyt, 2016). In this way images - unconsciously - force us all to retreat to our own interior worlds and to personal stories. A story, read or told, will evoke different "verbal images" in the mind of a reader or listener. Like visual images, the verbal image is coloured by one's life's experiences: “A simple way to summarize this point would be to say that we understand metaphors because we share experiences, and we come to experience the world a certain way as a result of how we metaphorize it." (Dolmage, 2005, p. 111). In imagery there is the opportunity to highlight or hide parts of the story that do not suit the author (Robertson, 1996; Dunn \& Burcaw, 2013).

Underhill (2011, p. 26) pointed to the fact that metaphors are not only based on one's personal experiences, but on shared experiences as well: "In a word, metaphors are embedded in networks of underlying conceptual equations." In this shared experience, however, lies ambiguity: unspoken suppositions about the experiences of the other may colour our interpretation of the metaphor or verbal image the other one uses. Family members are often more familiar with the experiences of a youngster with ID than professional support workers are, yet both should be aware of the dangers of making presumptions regarding the meaning of a metaphor.

When interpreting imagery, it becomes clear that ambiguity is an inherent and overarching theme: one recognises different pieces of information that the author may or may not have intended to convey. When interpreting a verbal or visual image created by a young person with ID, there is the unspoken invitation to translate the meaning of the image to the thought world of the family member or professional in the dialogue. However, that person has to be aware that this interpretation is tinted by his or her own experience; the young person with ID might have a different interpretation or purpose with the image or story. Being aware of one's own interpretive view and discussing that view with the young person with ID is needed to discover stories and explore different experiences.

\section{Choice}

"Während die Sprache eine sequenzielle Ordnung aufweise, zeichne sich das Bild durch eine Simultanität von Formen aus [Whilst speech evokes a sequential process of arrangement, the image shows itself through a simultaneity of forms]." (Traue, 2013, p. 120). Visual images can be frozen in time. To make them come to life, there is a need to connect and to construct visual objects. An image contains multiple objects made synchronously visible to us (Freedman \& Siegesmund, 2015). Unlike visual images, metaphors, stories, and other forms of verbal imagery are told in a sequential fashion. As the story develops, the receiving partner develops a mental image of the storyline, characters, and events. The concepts involved in story interpretation are similar to those 
used in image interpretation: there are concepts of form, emphasis, contrast, repetition, variation, and even "colour" (the different styles in which a story can be told). These concepts offer the other in the dialogue the choice to shift the focus during the interpretation, for example to deflect, intensify, or vivify. A clear example is found on Beau's blog. She metaphorises in one of her blogs how the expectations of others, but above all her own expectations, have affected her body and confronted her with her disability. She describes the negative effects, but uses self-mockery to convey the message that she rises above her disability. In discussing the confrontation, she chooses to highlight her achievements with her choice of words — "colour" — in the metaphor: "Body parts fly up and down without control, and my legs suddenly seem convinced they have done nothing but establishing records in running all my life. When I look at myself from a distance even I have to smile about it." (Beau, 2012b, sentences 7-8).

\section{Revelations}

Images, quite literally, offer the opportunity to see what the other saw or wants you to see. Like visual imagery, verbal imagery provides the opportunity to glimpse how the other experiences reality. The listener or reader expects to be able to relate to the story of the other, as Underhill (2011, p. 28) described: "We often experience metaphors as minor revelations. Intuition seems to be unveiling very real similarities in the world." Though the verbal imagery of the young person with ID may not always be coherent or complete, stories often reveal to the listener information about the inner world and daily life experiences of the young person - revelations that may be surprising and force the other to redefine thoughts. Between the interpreter and the interpreted material there is space for reflection and interpretation; Dewulf (2012) called this the "No-Man's Land" of imagery, which urges the interpreter to look for words or new images to be able to communicate about the interpretation. An image therefore evokes a natural reflexive process. As noted above, metaphors and verbal images are rooted in both individual and social concepts (Dolmage, 2005; Underhill, 2011). The recognition of these concepts, and at the same time the recognition of possible differences in interpretation, forces family members and professionals to reflect not only on the needs of the young person with ID, but on their own position and narrative in life as well. Imagery therefore relates to the inner self of the receiving partner. Any form of imagery evokes one's ability to connect one's own experiences to the narrative of the object at hand. Figure 3 is an example of how mind and body are intertwined in connecting to one's own experiences.

The lives and stories of young people with ID and their outlook on life harbour messages and surprises that may teach their families and professionals important lessons about their own lives. The researchers discussed how their work with young people with ID influenced their own convictions. A good example is provided by Beau (2012a) in one of her blog posts: "Except for the fact that we undoubtedly cost money, our unwillingly received life-experience ... yields a priceless treasure of information for any support worker" (para. 9). This quote moved the authors, since it clearly values the knowledge learned by experience; the realisation of the wealth of this 
knowledge changed how we, as researchers and practitioners, work together with people with disabilities.

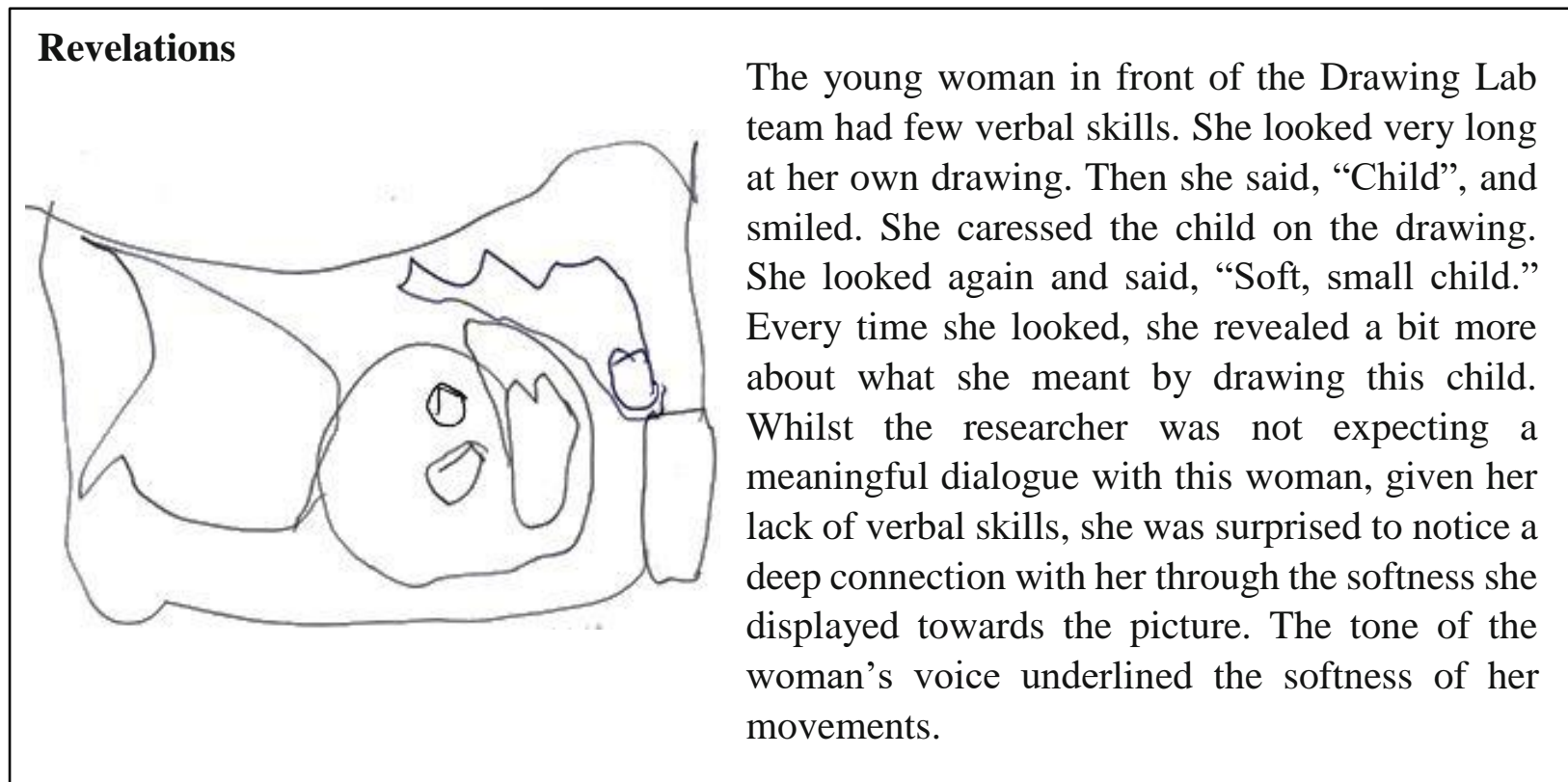

Figure 3. Vignette: Connection.

A visual image may protect the conversation partners from being too intrusive, since the image can be placed at the heart of the conversation. This gives the possibility of looking at the object instead of the conversation partner, but in a socially accepted manner: the so-called "180degree conversation". Instead of having to look directly at the other (which can be experienced as intrusive), one can look at the other via the medium of the picture. Since this process is mediated by the image-object, however, it can still feel safe, even if it is unsettling. Whereas visual images may create physical distance, verbal imagery creates mental distance from the subject at hand. "When we do not understand, we use metaphors, and they come to stand in for the literal truth, even in something as supposedly 'pure' and 'factual' as science." (Dolmage, 2005, p. 110).

Using images or metaphors also creates a certain distance from the intimate meaning of the message. The distance that comes into existence by talking about an object instead of directly talking about one's life allows less confrontational and intrusive communication:

The paper, or in this case the computer screen, has been my best friend for quite some time. If I am not understood, or if I do not want to tell something out loud, the figments of my imagery are penned on paper in no time. Paper is my portable therapist, and almost without costs. (Beau, 2010a, sentences 7-9) 


\section{Distance}

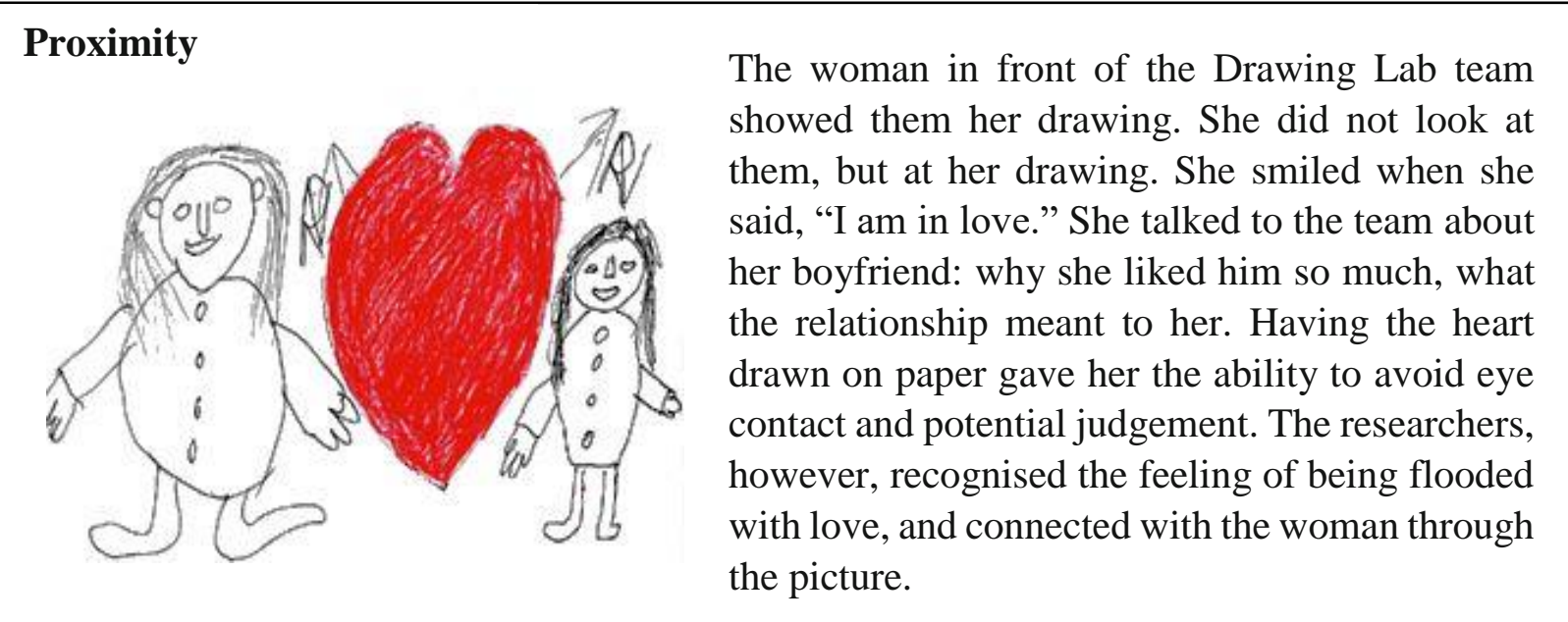

Figure 4. Vignette: Proximity.

Partners in dialogue can revisit the object, image, or story as a focus point in their conversation. Since it is inherent to a reflective process that people may wander from the core of the interpretation, or may have too many associations, both partners can use the object to return to the topic at hand. It may, however, be used as an escape as well: by exploring parts of the image, a painful or too intimate part of the story may be avoided or contained.

Distance not only creates safety, it also allows wonderment to emerge. The drawing or the metaphor becomes a "third party" in the conversation. It is something new that has been created, which has the possibility to surprise even the author by discovering unknown feelings, preferences, or even proportions. For example, the woman in the vignette described in Figure 4 was surprised to discover, while discussing her picture with the researcher, that she had drawn the heart so big it almost pushed the people off the paper.

Paradoxically, the distance created through using imagery has a strong potential to create connection. In discussing the theme "distance", the researchers realised that by using the safety and wonderment of distance, dialogue partners have the chance to intertwine and become allies: allies in conjoint beliefs, but in newly discovered stories and experiences as well. By discovering the story of the young person with ID, a family member or support worker has the chance to bridge their differences in life experiences.

\section{Discussion and Implications for Practice}

\section{Perspective}

In the practice of supporting young people with ID, challenges like tacit views, insecurity, time pressure, and presumptions call for a more intense elaboration on how to use imagery as a starting point for a joint reflective process. This article describes the critical dialogue of the 
authors. There are many similarities in the background of the authors. Since the reflexive process was based on their respective experiences and thoughts, the perspective of the dialogue is heavily embedded in the Dutch landscape and history of care. In addition the dialogue is based on only two research projects. However, the authors find that the challenge to connect and engage with young people with ID is universal, as is the power of the use of imagery. Further research should focus on the application of imagery in research with and support for young people with ID in different settings or from different perspectives.

The use of imagery offers clear possibilities for facilitating young people with ID to express themselves, and for connecting with them. While discussing their previous research, the authors found that essential conditions must be met if the use of imagery is to measure up to intentions. By discussing some keystone considerations in this section, the authors invite readers to reflect on the application of imagery in their own efforts to connect with young people with ID, taking into account their own specific circumstances and perspectives (see also Boxall \& Ralph, 2009).

\section{Enabling Environment}

In order to achieve an honest dialogue with young people with ID about their future, their dreams, and even their feelings about belonging (to a family, group, or society), the dialogue partner should be able and willing to embrace the use of enriching and deepening methods of communication such as patience, emotional support, and creativity, and of ways to make the environment more failure-free — when there is less chance for failure, there is less chance of being unable to participate. It is important for support workers to explore the concept of universal design as a framework for the establishment of an adaptive and inclusive environment for everyone, with or without disabilities. Universal design aims to have a truly inclusive society; to achieve this, one must view people with and without disabilities as equally normal. As Goodley and Runswick-Cole (2014, p. 13) wrote: "We want to move to a time when thinking about the human will always involve thinking about disability." The concept of universal design is reflected in Beau's (2010c) comment:

Another true wish of mine is that we will build more inclusive. Inclusive yes, not adapted. The expression "adapted" is out of place since in the use of "adapted" it is implied that certain groups still move outside society — not in it. If we adapt the entrance so you can enter the building: nice, but we should say: "If we build inclusive anyone can come inside the building." (para. 10)

Once these conditions are accepted as regular requirements for providing care through connectedness, one could speak of an "enabling environment".

\section{Practical Considerations}

The child shall have the right to freedom of expression: this right shall include freedom to seek, receive and impart information and ideas of all kinds, regardless of frontiers, either orally, in writing or in print, in the form of art, or through any 
International Journal of Child, Youth and Family Studies (2018) 9(4): 125-145

other media of the child's choice. (United Nations Children's Fund, 1990, article 13)

An enabling environment not only requires the right conditions and attitude for both dialogue partners, it also requires the right materials to express their image or story. Qualitatively good and diverse materials are essential to the process of making an average exchange of ideas into a true dialogue. Having sufficient time is important as well. Even though Lewis et al. (2016) explain that lack of time is not the core factor in communication barriers, having sufficient time surely is a prerequisite if a true dialogue is to develop.

\section{Presuming Competence}

If you are interested in seeing another's competence, it helps to look for it. (Biklen \& Kliewer, 2006, p. 184)

Despite their apparent deficits in cognitive skills, young people with ID are more than capable of expressing themselves in diverse and colourful ways, provided they are given the opportunity. In order to allow young people to make use of these ways of expression, however, the partner in the dialogue must first presume competence in the youngster with ID. "Intimate contact with the person and openness to the person allows you to dispense with the fault-finding, deficitseeking framework of the professional diagnostician and to learn about the person through engagement" (Goode, 1992, in Biklen \& Kliewer, 2006). For families, friends, and support workers to really connect and communicate with young people with ID on existential themes, it is essential that their preferred way of communication be followed. Communication partners must presume that young people with ID are competent to paint a picture about what they want in life.

\section{Belonging}

Recently, views of reciprocity and connectedness have often been incorporated in models that target the quality of support; for example, "positive health" (Huber et al., 2016), "humane care" (Van Heijst, 2005; Embregts \& Hendriks, 2011), and "presence theory" (Baart, 2004). The authors, too, encountered these concepts in their respective research processes and experiences.

Using imagery shows great promise to foster belonging through meaningful dialogue with the young person, as it can shape the emotional and conjunctive power of that dialogue. However, it is important to notice that belonging is reciprocal in nature. In society, young people with ID are often perceived as the partner that "takes": for them to experience belonging, it is important that family members and support workers are open to "receive" from young people as well. For example, the Drawing Lab research revealed that young people with ID did not make drawings about the support they received. Instead, they drew about what they can give, what they mean to people, or about their frustration that they cannot engage (yet) in certain relationships or in meaningful work. 
International Journal of Child, Youth and Family Studies (2018) 9(4): 125-145

\section{Ownership}

There is a clear need for the person with ID to feel peacefully in control of the dialogue. Life experiences have taught them that compared to others, they are often less able to exert power. The other - the support worker, the teacher, the parent — is the one who knows better, while the young person with ID is the person who receives instruction. Choosing to follow the story and interpretation of a person with ID asks caregivers, who often have learned to interpret stories in the light of their own acquired knowledge, to be brave. In order for somebody to be thought of as a fully competent participant in a relationship, they have to be seen as contributing something to the partnership (Bogdan \& Taylor, 1989). The mere choice of the image or story to reflect on is an act of exchange: what is the person with ID trying to communicate to the other by choosing that object? What does the image — the made-up lullaby one's mother sang, the photographs of the house one grew up in, the artwork one made at the activity centre - truly mirror about how the person feels about himself or herself? Being able to decide the medium for communication puts the young person with ID in charge of the conversation. The person with disability, the client, is now "owner" of the depiction at hand. So in talking to young people with ID, the dialogue partner should be prepared to step down from the position of leader to a position of co-pilot in the process of reflection.

\section{Rocky Road}

In a dialogue on existential themes, there is a need for listening, for true interest, and for having the will to get to know the inner world of the other. Whereas family members are confronted with the birth of a child with ID, and the consequent appeal for care, professional support workers tend to choose to work in the care system. Research about the motivations of support workers indicates that the tacit views they hold influence the way they approach their clients or patients (Lewis et al., 2016; Dowse, 2012). In the practice of their work, they may be confronted with these views when young people with ID behave differently than expected. Van Den Brande (2012) states that inclusion is a fundamental right that evolves around "belonging" and "connectedness": inclusion is by definition a relational concept. An honest dialogue may be upsetting or unsettling for the youngster with ID - yet the right to have an upsetting or unsettling dialogue is part of inclusion. Moreover, in an honest dialogue the other partner may be touched as well, or even unsettled or upset; looking for inclusion is not a straightforward process. It may at times be a rocky road, but it is one worth travelling.

\section{Tacit Knowledge}

There is no medium of expression that is equally suited for all learners or for all kinds of communication. (Florian, 2014, p. 482)

Young people with ID are experts by experience at living with ID in a complex society. Their support workers lack this experience. Further research should focus on how the young people's tacit knowledge can be made visible, and how this knowledge can be applied in society 
International Journal of Child, Youth and Family Studies (2018) 9(4): 125-145

to enhance the QOL of others. Research on how young people with ID can be encouraged to take a formal or informal role as teacher and guide for support workers is therefore recommended.

\section{Conclusion}

By comparing their respective independent research and experiences as separate cases, the authors found that using imagery is a powerful method to engage people with disabilities in research, as well as a meaningful way for family members and support workers to engage with young people with ID. A critical dialogue was used to compare cases, thoughts, experiences, and critical incidents; this led to the identification of five themes that emerged from the dialogue. The theme of the leitmotiv shows that imagery offers the possibility of finding respite from anxiety in a dialogue, knowing that a core set of beliefs, subjects, and ideas will resurface once the drawing or the story is revisited. That images can be interpreted in different ways is shown in the theme of ambiguity, where the authors found that discussing these different interpretations establishes a swift connection between dialogue partners. Imagery also offers the option of choice: the author, as well as the interpreter, may choose to highlight certain important parts of the image, or to hide painful or undesired parts. The fourth theme concerns imagery's power of revelation, be it small or grand. The use of imagery offers the possibility of revealing new information, talents, or questions that the dialogue partners had not previously discussed. Distance is the final theme discussed in the article. The use of imagery offers safety: first, through creating a dialogic space where a 180-degree conversation is permissible, and second, in offering a safe object to talk about, a concrete focal point. Imagery not only creates safety in offering distance, however; it also is a suitable way of decreasing distance between two dialogue partners, in that shared experiences or ideas evoke recognition.

Young people with ID, though sometimes limited in verbal skills, have no less of an inner world than do young people without disabilities. They possess reflective power on their position in life and society, and their needs, experiences, and wishes. Indeed, their very age calls for an open dialogue on life, since it is one of the developmental tasks of young people to wonder and ponder on their future. In the Netherlands, the changing landscape of care and support strategies places more emphasis on the need to connect with the inner world of young people with ID. The fast pace of Dutch society, however, and excessive reliance on instrumental communication in offering support, pose a threat to the realisation of this connection.

Imagery connects dialogue partners and creates space for safe exchange and exploration on existential themes. Based on the findings from the critical dialogue discussed in this article, there is a strong argument for applying more diverse forms of imagery in research and practice, in order to bridge the distance between caregivers and persons with ID when talking about existential questions regarding life, purpose, and meaning, as well as more practical questions that require reflection. 
International Journal of Child, Youth and Family Studies (2018) 9(4): 125-145

It is also important to emphasise that using all possible ways to communicate is not a "special treatment" to be reserved for young people with ID. In a way, one could see dialogue with young people with ID as an example of good communication in the broadest sense: moving away from the idea of the exclusivity of spoken and written language and towards the idea of using any and all forms of representation to build connection with other people. 
International Journal of Child, Youth and Family Studies (2018) 9(4): 125-145

\section{References}

Atkinson, D. (2005). Narratives and people with learning disabilities. In G. Grant, P. Goward, P. Ramcharan, \& M. Richardson (Eds.), Learning disability: A life cycle approach to valuing people (pp. 7-27). Maidenhead, UK: Open University Press.

Baart, A. (2004). Een theorie van de presentie [Presence theory]. Amsterdam: Boom Lemma Uitgevers.

Beau (2010a, May 26). Schrijven is de goedkoopste geneesheer [Writing is the cheapest doctor; Blog post]. Retrieved from http://britthoms.blogspot.nl/2010/05/

Beau (2010b, May 30). Mary [Blog post]. Retrieved from http://britthoms.blogspot.nl/2010/05/

Beau (2010c, November 9). Been there, done that, bought the t-shirt [Blog post]. Retrieved from http://britthoms.blogspot.nl/2010/11/been-there-done-that-bought-t-shirt.html

Beau (2012a, July 4). Zorg anno 2016: Professional versus vrijwilliger [Care in 2016:

Professional versus volunteer; Blog post]. Retrieved from

http://britthoms.blogspot.com/2012/07/zorg-anno-2016-professional-versus.html

Beau (2012b, September 5). Sommige dingen wennen niet [Some stuff you can't get used to; Blog post]. Retrieved from http://britthoms.blogspot.nl/2012/09/sommige-dingen-wennen$\underline{\text { niet.html }}$

Biklen, D., \& Kliewer, C. (2006). Constructing competence: autism, voice and the 'disordered' body. International Journal of Inclusive Education, 10(2-3), 169-188. doi:10.1080/13603110600578208

Bogdan, R., \& Taylor, S. J. (1989). Relationships with severely disabled people: The social construction of humanness. Social Problems, 36(2), 135-148. doi:10.2307/800804

Boxall, K., \& Ralph, S. (2009). Research ethics and the use of visual images in research with people with intellectual disability. Journal of Intellectual \& Developmental Disability 34(1), 45-54. doi:10.1080/13668250802688306

Brants, L., van Trigt, P., \& Schippers, A. (2016). Handicap in Nederland. In G. Van Hove, A. Schippers, M. Cardol, \& E. de Schauwer (Eds.), Disability Studies in de Lage Landen [Disability studies in the Low Countries] (pp. 320-333). Antwerp, The Netherlands: Garant.

Dewulf, B. (2012). Verstrooiingen: over Kijken en Zien [Scatter: About looking and seeing]. Amsterdam, The Netherlands: Atlas Contact. 
International Journal of Child, Youth and Family Studies (2018) 9(4): 125-145

De Waele, I., van Loon, J., Van Hove, G., \& Schalock, R. L. (2005). Quality of life versus quality of care: Implications for people and programs. Journal of Policy and Practice in Intellectual Disabilities, 2(3/4), 229-239. doi:10.1111/j.1741-1130.2005.00035.x

Dolmage, J. (2005). Between the valley and the field: Metaphor and disability. Prose Studies, 27(1-2), 108-119. doi:10.1080/01440350500068973

Dowse, L. (2009). 'Some people are never going to be able to do that'. Challenges for people with intellectual disability in the 21st century. Disability \& Society, 24(5), 571-584. doi:10.1080/09687590903010933

DSiN. (2016). Disability studies in Nederland code of practice for researchers 2016-2017. Retrieved from https://disabilitystudies.nl/code-practice-researchers

Dunn, D. S., \& Burcaw, S. (2013). Disability identity: Exploring narrative accounts of disability. Rehabilitation Psychology, 58(2), 148-157. doi:10.1037/a0031691

Embregts, P., \& Hendriks, L. (2011). Menslievende professionalisering in de zorg voor mensen met een verstandelijke beperking [Humanitarian professionalization in the care for people with a mental disability]. Arnhem, The Netherlands: HAN University Press.

Florian, L. (2014). The SAGE handbook of special education. London, UK: Sage Publications.

Freedman, K., \& Siegesmund, R. (2015). Creating and analyzing the visual in research. Workshop given at the Eleventh International Congress of Qualitative Inquiry, University of Illinois at Urbana-Champaign, IL.

Freire, P. (2005). Pedagogy of the oppressed. New York, NY: Continuum.

Goodley, D., \& Runswick-Cole, K. (2014). Becoming dishuman: Thinking about the human through dis/ability. Discourse: Studies in the Cultural Politics of Education, 37, 1-15. doi:10.1080/01596306.2014.930021

Hermans, C. (2016). Differences in itself: Redefining disability through dance. Social Inclusion, 4(4), 160-167. doi:10.17645/si.v4i4.699

Hoppe, S. (2012). Pleidooi voor agency [Plea for agency]. In ZonMw \& Disability Studies in Nederland, Kijk anders, Zie meer [See different, see more] (pp. 129-140). Rijswijk, The Netherlands: Quantes.

Howe, B., Jensen-Moulton, S., Lerner, N., \& Straus, J. (2015). The Oxford handbook of music and disability studies. Oxford, UK: Oxford University Press. 
International Journal of Child, Youth and Family Studies (2018) 9(4): 125-145

Huber, M., van Vliet, M., Giezenberg, M., Winkens, B., Heerkens, Y., Dagnelie, P. C., \& Knottnerus, J. A. (2016). Towards a 'patient-centred' operationalisation of the new dynamic concept of health: A mixed methods study. British Medical Journal 6(1). doi:10.1136/bmjopen-2015-010091

IASSIDD SIRG-QOL (International Association for the Scientific Study of Intellectual Disabilities Special Interest Research Group on Quality of Life). (2000). Quality of life: Its conceptualization, measurement, and application: A consensus document. Retrieved from http://www.iassidd.org/content/QOL Consensus Document 2000

Karlsson, O. (2001). Critical dialogue: Its value and meaning. Evaluation, 7(2), 211-227. doi:10.1177/135638900100700206

Lewis, P., Gaffney, R. J., \& Wilson, N. J. (2016). A narrative review of acute care nurses' experiences nursing patients with intellectual disability: Underprepared, communication barriers and ambiguity about the role of caregivers. Journal of Clinical Nursing, 26(11-12), 1473-1484. doi:10.1111/jocn.13512

Nelson, L. L. (2014). Design and deliver: Planning and teaching using Universal Design for Learning. Baltimore, MD: Paul H. Brookes.

Null, R. (2013). Universal design: Principles and models. Boca Raton, FL: CRC.

Robertson, C. (1996). The healing power of metaphor. Stellenbosch Papers in Linguistics Plus, (29), 191-211.

Scher, S. P. (2004). Literature and music (1982). In W. Bernhart \& W. Wolf (Eds.), World and music studies: Vol. 5. Essays on literature and music (1967-2004) (pp. 173-202). Amsterdam, The Netherlands: Rodopi.

Sergeant, S., \& Verreyt, L. (2016). De dialoog ondertiteld met beelden [The dialogue subtitled with images]. In G. Van Hove, A. Schippers, M. Cardol, \& E. de Schauwer (Eds.), Disability studies in de Lage Landen (pp. 151-190). Antwerp, The Netherlands: Garant.

Smaling, A. (2008). Dialoog en empathie in methodologie [Dialogue and empathy in methodology]. Amsterdam, The Netherlands: SWP, Humanistics University Press.

Speet., M., \& Rijken, P. M. (2005). Participatie van mensen met een verstandelijke beperking in de samenleving: Een ontwerpstudie [Participation of people with an intellectual disability in society: A design study]. Utrecht, The Netherlands: National Institute for Health Services Research (NIVEL).

Stanczak, G. C. (2007). Visual research methods. Los Angeles, CA: Sage. 
International Journal of Child, Youth and Family Studies (2018) 9(4): 125-145

Stefán, S. (2010). Metaphors, narratives, emotions: Their interplay and impact. Amsterdam, The Netherlands: Brill Academic.

Thomas, D. R. (2006). A general inductive approach for analyzing qualitative evaluation data. American Journal of Evaluation, 27(2), 237-246. doi: 10.1177/1098214005283748

Traue, B. (2013). Visuelle Diskursanalyse. Ein programmatischer Vorschlag zur Untersuchung von Sicht- und Sagbarkeiten im Medienwandel [Visual discourse analysis. A programmatic proposal for the research of visibility and speakability in media change]. Zeitschrift für Diskursforschung, 2(1), 117-136.

Underhill, J. W. (2011). Creating worldviews: Metaphor, ideology and language. Edinburgh, UK: Edinburgh University Press.

United Nations Department of Economic and Social Affairs. (n.d.). Factsheet definition of youth. Retrieved from https://www.un.org/esa/socdev/documents/youth/fact-sheets/youthdefinition.pdf

United Nations Children's Fund. (1990). Convention on the Rights of the Child [report]. Retrieved from http://www.ohchr.org/Documents/ProfessionalInterest/crc.pdf

Van Den Brande, J. (2012). Identiteit en constructie van handicap [Identity and construction of disability]. Paper presented at the meeting of Open-Grip-Dag, Mechelen, Belgium.

Van Heijst, A. (2005). Menslievende zorg: Een ethische kijk op professionaliteit [Humanitarian care: An ethical look at professionalism]. Utrecht, The Netherlands: Klement.

Wang, C. C., Yi, W. K., Tao, Z. W., \& Carovano, K. (1998). Photovoice as a participatory health promotion strategy. Health Promotion International, 13(1), 75-86.

doi:10.1093/heapro/13.1.75

Williams, V. (2011). Disability and discourse: Analysing inclusive conversation with people with intellectual disabilities. London, UK: Wiley-Blackwell. 